\title{
FREQUENCY AND DISTRIBUTION OF CYTOPLASMIC AND NUCLEAR P63 IN RECOGNIZING THE BASAL-LIKE AND NON-BASAL-LIKE TYPES OF BREAST CANCER BASED ON AGE
}

\author{
RENO KEUMALAZIA KAMARLIS ${ }^{1}$, MUHAMMAD NADJIB DAHLAN LUBIS ${ }^{2}$, BETHY S HERNOWO ${ }^{3}$, AZMI S KAR ${ }^{4}$, \\ BASRI A GANI ${ }^{5 *}$
}

${ }^{1}$ Department of Pathology Anatomy, Medical Faculty, Syiah Kuala University, Banda Aceh, Indonesia. ${ }^{2}$ Department of Pathology Anatomy, Medical Faculty, Sumatera Utara University, Medan, Indonesia. ${ }^{3}$ Department of Pathology Anatomy, Medical Faculty, Padjajaran University, Bandung, Indonesia. ${ }^{4}$ Department of Internal Medicine, Medical Faculty, Sumatera Utara University, Medan, Indonesia. ${ }^{5}$ Department of Biology Oral, Dentistry Faculty, Syiah Kuala University, Banda Aceh-Indonesia, Indonesia. Email: basriunoe@gmail.com

Received: 06 September 2017, Revised and Accepted: 10 October 2017

ABSTRACT

Objective: To assess the immune expressions of cytoplasmic and nuclear protein63 (p63) proteins in metaplastic triple-negative breast cancer (TNBC) patients with basal-like and non-basal-like types based on age.

Methods: Forty samples of breast cancer patients diagnosed with TNBC were examined immune histochemical based on the immune expressions of cytoplasmic and nuclear p63 with basal-like (CK 5/6, positive) and non-basal-like (CK 5/6 negative) types. The histoscore values were categorized into Score $1(<20 \%$, negative), Score 2 ( $>20 \%-50 \%$, weak positive), Score $3(>50 \%-80 \%$, moderate positive), and Score 4 ( $>80 \%$, strong positive) also analyzed by one-way analysis variance, probability $(\mathrm{p}<0.05)$, and correlation $(\mathrm{p}<0.01)$

Results: Forty subjects with breast cancer showed 23 of basal-like (57.5\%) and 17 of non-basal-like (42.5\%) types. The cytoplasmic p63 had a low histoscores in the group of $<40-49$ years old (55\%), the moderate group of 40-55 years old (27.5\%), and the high group of fewer than 50-60 years old (17.5\%). The nuclear p63 was low in all age groups $(\mathrm{p}<0.05)$. It was the significant difference between basal-like and non-basal-like types ( $<0.01$ ) and strongest correlation (1.00). The immunoexpression of cytoplasmic p63 of basal-like cell type had an intensity of $88.2 \%$, while nuclear p63 possessed $11.8 \%(\mathrm{p}<0.05)$

Conclusion: The frequency of cytoplasm p63 in all age groups of metaplastic breast cancer of basal-like type was more dominant than the nuclear p63. Otherwise, in the non-basal-like type, the cytoplasmic p63 protein was lower than the of nuclear p63 protein.

Keywords: Cytoplasmic protein63, Nuclear protein63, Metaplastic breast cancer, Basal-like, Non-basal-like.

(C) 2018 The Authors. Published by Innovare Academic Sciences Pvt Ltd. This is an open access article under the CC BY license (http://creativecommons. org/licenses/by/4. 0/) DOI: http://dx.doi.org/10.22159/ajpcr.2018.v11i1.22415

\section{INTRODUCTION}

Breast cancer is generally considered as the most commonly found cancer in women, reaching a million more worldwide [1]. The number of breast cancer patients in a year is estimated to be about 400,000 patients [2]. Risk factors for breast cancer are mostly associated with hormonal and genetic factors also smoking [3]. The most common breast cancer is triple-negative breast cancer (TNBC) that demonstrate the absence of estrogen receptor and progesterone receptor and no overexpression of human epidermal growth factor receptor 2 (HER2) [4].

Breast cancer, moreover, is treated based on the biological characteristics of tumor used for its prognosis. To detect breast cancer early, biomarkers, as the development of molecular concepts, are used with both immunohistochemical method and biomarker proteins [4]. The concept of biomarkers is related to the immunoexpression of oncogenic proteins with receptors of specific markers. One of the markers being developed is protein 63 (p63) as a transformation-related p63, a protein in humans encoded by tumor p63 (TP63) genes [5].

TP63, the family of p53, is a suppressor tumor gene together with p73, having the same structure [6]. P63 gene expression in squamous cell carcinoma shows that the p63 gene acts as the oncogene and cannot be used to predict malignant transformation of the sinonasal papilloma [7]. TP63 is a nuclear marker of the myoepithelial cells, and the antibody to p63 is frequently used to diagnose cancer, especially in metaplastic breast cancer. The calponin, CD10, and p63 are the basal cell markers of myoepithelial cells protein used to detect the early breast tumor [8] also T47D and MCF-7 cells as a marker for detecting the breast cancer [9].

Furthermore, p63 protein has a sensitivity of $86.7 \%$ and a specificity of $99.4 \%$ in diagnosing metaplastic carcinoma. Thus, p63 protein is possible to be used to diagnose breast tumors, specifically for metaplastic carcinoma [8]. Immunohistochemistry is one of the methods used to detect p63 protein in breast cancer with a strong sensitivity to basal-like type [10].

In addition, p63, a p53 homolog protein is a good selective nuclear marker of myoepithelial cells in breast cancer [11]. TNBC is molecularly closed to basal-like molecular phenotypes [12].

However, expression of cytoplasmic and nuclear p63 markers of the basal-like type still has not been found in metaplastic carcinoma. Research on the sensitivity degree of cytoplasmic and nuclear p63 marker specifically of basal-like and non-basal-like types was not yet reported. In this research, focuses the accuracy applied to basal-like and non-basal-like types of cytoplasmic and nuclear p63 based on ages. It could be helping to detect early breast cancer is precisely and accurately to prevent the breast cancer spreads in human. Therefore, this research aimed to assess the immunoexpression of cytoplasmic and nuclear p63 proteins in metaplastic triplet-negative breast cancer patients with basal-like and non-basal-like types based on age. 


\section{METHODS}

\section{Materials}

This research has approved with the ethical clearance No.103/KOMET/ FK-USU/2015 issued by Faculty of Medicine, University of Sumatera Utara, Medan Indonesia. Research subjects were 40 metaplastic breast cancer patients with TNBC carcinoma hospitalized in Hospital Dr. Hasan Sadikin, Bandung Indonesia. Those patients, then, were diagnosed with immunohistochemical techniques to determine the immunoexpression of cytoplasmic and nuclear p63 with basal-like and non-basal-like types.

\section{Immunohistochemical assay}

The immunoexpression of cytoplasmic and nuclear p63 was identified by immunohistochemistry assay using kits ®Biocare Medical, Pacheco, CA, USA. In the first stage, 40 tissue samples taken from those breast cancer patients with TNBC were prepared in paraffin preparations. Each of those tissue samples sized $4 \mu \mathrm{m}$ was cut from each patient with a microtome blade, and then put into a preparation attached to an object glass, and heated on a hot plate temperature of $56-60^{\circ} \mathrm{C}$ for $10 \mathrm{~min}$. Second, those tissue samples were incubated for $24 \mathrm{~h}$ at $37^{\circ} \mathrm{C}$. Third, deparaffinization was performed by dipping them sequentially in xylol 3 times, each of which was for about 5 min. Fourth, rehydration was conducted by dipping them in $100 \%$ ethanol 3 times, each of which was for about $5 \mathrm{~min}$. Fifth, they were immersed in $0.3 \%$ hydrogen peroxide in methanol for $15 \mathrm{~min}$. Sixth, they were inserted into $90 \%$, $80 \%$, and $70 \%$ alcohols, respectively, for $5 \mathrm{~min}$, and then washed in running water for $5 \mathrm{~min}$ [13].

Next, immunohistochemical examination was started with a chamber/ microwave process using a retrieval antigen solution (Biocare Medical, Pacheco, CA, USA) for $35 \mathrm{~min}$ at $92^{\circ} \mathrm{C}$, then washed with distilled water for $5 \mathrm{~min}$, and dried [5]. Afterward, the preparations were encircled with Pap-pen around the tissue piece to be examined and then washed with phosphate buffer saline (PBS) for $5 \mathrm{~min}$. In the next step, a block with a sniper blocking solution and 10 min incubation was performed. The subsequent process of basal-like determination was carried out by adding $100 \mu \mathrm{l}$ of CK 5/6 solution on each preparation with a positive (basal-like absorbing the dye solution) and negative (non-basal-like absorbing no dye solution) [14].

After that, the determination of p63 immunoexpression was performed using the working principle of Zheng et al.[15]. On each preparation, $100 \mu \mathrm{l}$ of p63 protein was dripped evenly, incubated for $1 \mathrm{~h}$, and then washed with PBS with a pH of 7.2-7.4 twice for 5 min. Next, those were labeled with secondary antibody, then incubated for 10-20 min, and washed again with PBS with a pH of 7.2-7.4 twice for 5 min. Afterward, those were dripped with $100 \mu \mathrm{l}$ of Starr Tracks Universal HRP Detection, then incubated for 10-20 min, and washed with PBS with a pH of 7.27.4 twice for $5 \mathrm{~min}$

In the final stage, they were dripped with $100 \mu \mathrm{l}$ of DAB solution for $5 \mathrm{~min}$ and washed in running water for $5 \mathrm{~min}$. Next, the counterstaining process was conducted using Mayer Hematoxylin staining for 2 min and then washed with 5 min running water. Afterward, they were dipped in lithium carbonate and washed with running water. Dehydration process, then, was performed by immersing them into alcohol $70 \%$, $80 \%$, and $90 \%$, respectively, for $5 \mathrm{~min}$. After that they were dipped in ethanol for $5 \mathrm{~min}$, then inserted in xylol, and washed for $5 \mathrm{~min}$. Each of samples than was covered with a glass cover glued with entraining [16].

\section{Immunohistochemical assessment}

Results of the histoscore reading on each slide preparation were interpreted by assessing the percentage of stained cell distribution (at the nucleus or cytoplasm) multiplied by the intensity values (positive and negative) [17]. The analysis of the immunohistochemical assessment results on p63 immunoexpression as follows: (Total score $=16)$; $($ Histoscore $=$ Distribution $\times$ Intensity); and (Average $=1-16)$. Histoscore calculation formula based on distribution and intensity used was categorized into Score 1 indicated to be negative $(<20 \%)$, Score 2 indicated to be positive weak $(>20-50 \%)$, Score 3 indicated to be moderate positive ( $>50-80 \%$ ), and Score 4 indicated to be strongly positive $(>80 \%)$.

\section{Statistical analysis}

The immunoexpressions of cytoplasmic and nuclear p63 in those metaplastic breast cancer patients with basal-like and non-basal-like types were analyzed by one-way analysis variance with a probability value of $\mathrm{p}<0.05$ and a correlation value of $\mathrm{p}<0.01$

\section{RESULTS AND DISCUSSION}

\section{Statistical analyses}

The research subjects consisted of five people aged $<40$ years old, 11 people aged 40-49 years old, 13 people aged $50-59$ years old, and 11 people aged $>60$ years old. The results of the examination on the 40 research subjects indicated that 23 subjects had basal-like cells (57.5\%) with positive CK5/6, and 17 subjects had non-basal-like cells (42.5\%) with negative CK 5/6. Based on results of the correlation analysis using Kappa value, there was a significant difference between basal-like and non-basal-like $(\mathrm{p}<0.01)$ with a very strong correlation $(1.00)$. Whereas based on results of the Mann-Whitney's analysis, furthermore, there was a significant difference in the immunoexpression of cytoplasmic p63 between the basal-like and the non-basal-like types ( $p<0.05)$. Meanwhile, there was no significant difference in the immunoexpression of nuclear p63 between the basal-like and the non-basal-like types ( $p>0.05)$. In general, the results also indicated that there was a significant difference between cytoplasmic p63 and nuclear p63 $(\mathrm{p}<0.05)$.

\section{Distribution of samples}

Table 1 summarizes that the distribution of cytoplasmic p63 immunoexpression in those 40 subjects was generally weak in the group of 40-49 years. Meanwhile, in the group of 50-60 years, the distribution of cytoplasmic p63 immunoexpression was high. Therefore, it can be said that the distribution of cytoplasmic p63 immunoexpression may be affected by age, especially in breast carcinoma with basal-like type. Unlike the results of this research, the p63 was used as the myoepithelial marker to diagnose metaplastic carcinoma with a sensitivity of $65 \%$, a specificity of $96 \%$, a positive predictive value of $96 \%$, a negative predictive value of $66 \%$, and an accuracy of $78 \%$ [18].

The discrepancy of these findings can be assumed that age is a determinant factor of p63 immunoexpression in breast cancer with both basal-like and non-basal-like types. The weak frequency of p63 immunoexpression was found in the group of breast cancer with basal-like type aged 40-49 years. Meanwhile, the high frequency of p63 immunoexpression was found in the group of breast cancer with basal-like type aged 50-60 years old. The basal-like and TNBC were associated [19]. In addition, the expression of p63 protein derived from basal epithelial cells is strongly influenced by the intensity of tumor cell development such as cell nutrition factor [20], chemotherapy, regulation, and p63 protein synthesis [21] both in nucleus and cytoplasm [22].

\section{Frequency histoscore of breast cancer types}

In the basal-like type, a cytoplasmic p63 protein was more dominant than nuclear p63 protein. However, in the non-basal-like type, a cytoplasmic p63 protein was lower than nuclear p63 protein (Fig. 1). The p63 protein is a marker of squamous cell carcinoma at subcellular normal cells or hyperplastic ones appearing significantly in the epithelial cells and contributing to the increased invasion and aggressiveness of the tumor [22]. Specifically, the results of this research indicated that the sensitivity and specificity of cytoplasmic $\mathrm{p} 63$ protein in metaplastic breast cancer with basal-like type was $88.2 \%$, while the sensitivity and specificity of nuclear p63 protein was $11.8 \%$. Unlike this research, the sensitivity and specificity of p63 as a diagnostic marker in metaplastic carcinoma reached $86.7 \%$ and $99.4 \%$ [23]. In addition, p63 can also be considered as a specific marker in metaplastic carcinoma. In cases of TNBC breast cancer, breast tumor can specifically identify with basallike type markers due to the intensity of expressions derived from the basal-like growth factor receptor 2 (HER2) of tumor cells [24]. 
Table 1: Distribution of immunoexpressions of cytoplasmic and nuclear p63 in metaplastic breast cancer

\begin{tabular}{llllll}
\hline Histo score & Frequency (n) Cytoc-Nuc & Percentage (\%) Cytoc-Nuc & Age (year) Cytoc-Nuc & Type (n) \\
\cline { 4 - 6 } & & & BL-NBL & Cytoc & Nuc \\
\hline Low $(\leq 5)$ & & & $(<40-49)-(<40->60)$ & $(15)-(7)$ & $(23)-(17)$ \\
Moderate $(\geq 6-10)$ & $(22)-(40)-(0)$ & $(55)-(100)$ & $(40-55)-(0)$ & $(6)-(5)$ & 0 \\
High $(\geq 11-16)$ & $(7)-(0)$ & $(27,5)-(0)$ & $(50-60)-(0)$ & $(5)-(2)$ & 0 \\
Total & $(40)-(40)$ & $(17,5)-(0)$ & $(<40->60)-(<40->60)$ & $(26)-(14)$ & $(23)-(17)$ \\
\hline
\end{tabular}

BL: Basal-like, NBL: Non-basal-like, Cytoc: Cytoplasmic, Nuc: Nuclear

\section{Immunohistochemical analyses}

Pregnancy is often associated with breast cancer, generating mortality risk that conducting prognosis is one of the efforts to assess the development of breast cancer $[25,26]$. One of the techniques used to conduct the prognosis is using a marker to detect immunohistochemically. Marker not only has certain characteristic properties but also has predictive character toward the sensitivity and specificity of breast tumors with specific types [27]. TP63, on the other hand, is a nuclear marker of myoepithelial cells frequently expressed on basal epithelial cells of tumors. Thus, p63 antibodies can specifically be used as markers to detect the presence of carcinoma, including breast cancer [28].

The immunoexpressions of cytoplasmic and nuclear p63 with basallike and non-basal-like types were detected by immunohistochemical techniques (Fig. 2). In the basal-like cell type, the immunoexpression of cytoplasmic p63 had an intensity of $88.2 \%$, while nuclear p63 had an intensity of $11.8 \%$. On the other hand, in the non-basal-like type, there was no intensity of both cytoplasmic and nuclear p63 identified. The cytoplasmic p63 protein is always associated with increased cancer mortality characterized by decreased apoptosis and increased proliferation activities of cancer cells [29]. Meanwhile, nuclear p63 protein is associated with oncogenic changes, and it has a lower sensitivity as a tumor marker than cytoplasmic p63 protein [30]. It means that cytoplasmic p63 protein has better sensitivity as a marker of metaplastic breast cancer. As a result, cytoplasmic 663 protein can be used as a prognosis for detecting metaplastic breast cancer with basallike type.

Fig. 2 represented the immunoexpressions of cytoplasmic and nuclear p63 in basal-like and non-basal-like cells using immunohistochemical techniques. In the basal-like cell type, the immunoexpression of cytoplasmic p63 had an intensity of $88.2 \%$, while nuclear p63 had an intensity of $11.8 \%$. On the other hand, in the non-basal-like type, there was no intensity of both cytoplasmic and nuclear p63 identified. In other words, Fig. 2 demonstrated that in the basal-like cells, the immunoexpression of cytoplasmic p63 (B) was higher than nuclear p63 (A). In contrast, in the non-basal-like cells, both of cytoplasmic and nuclear p63 were low (C and D).

\section{DISCUSSION}

Pregnancy is often associated with breast cancer, generating mortality risk [18]. Conducting prognosis is one of the efforts to assess the development of breast cancer [19]. One of the techniques used to conduct the prognosis is using a marker to detect immunohistochemically [2]. Marker not only has certain characteristic properties but also has predictive character toward the sensitivity and specificity of breast tumors with specific types $[20,21]$. TP63, on the other hand, is a nuclear marker of myoepithelial cells frequently expressed on basal epithelial cells of tumors. Thus, p63 antibodies can specifically be used as markers to detect the presence of carcinoma, including breast cancer.

Table 1, moreover, summarized that the distribution of cytoplasmic p63 immunoexpression in those 40 subjects was generally weak in the group of 40-49 years. Meanwhile, in the group of 50-60 years, the distribution of cytoplasmic p63 immunoexpression was high. Therefore, it can be

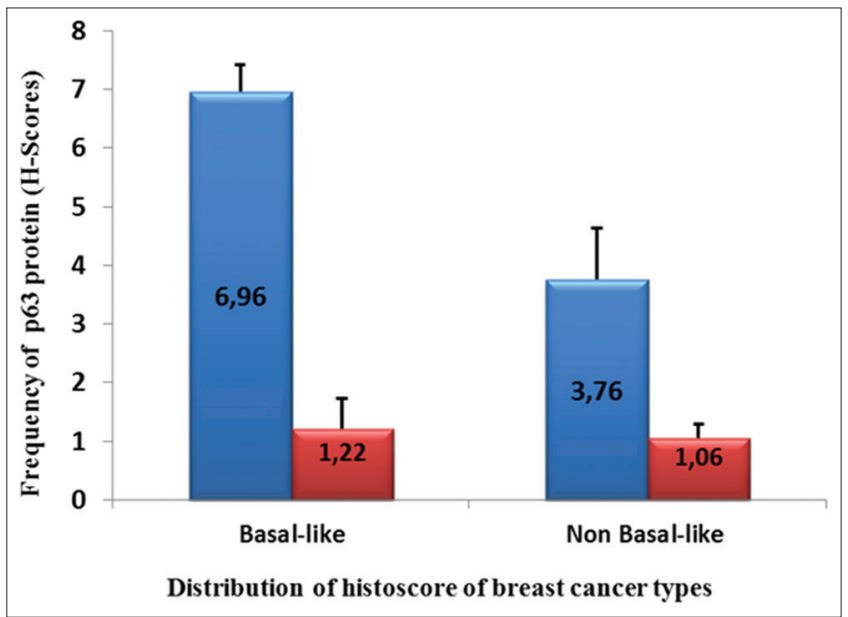

Fig. 1: The immunoexpression frequency of cytoplasmic and nuclear p63 in metaplastic breast cancer types of basal-like, $n=40$ (blue bar) and non-basal-like, $\mathrm{n}=40$ (red bar), where, bar (the average of histoscores) and error bar (the average of standard deviation values)

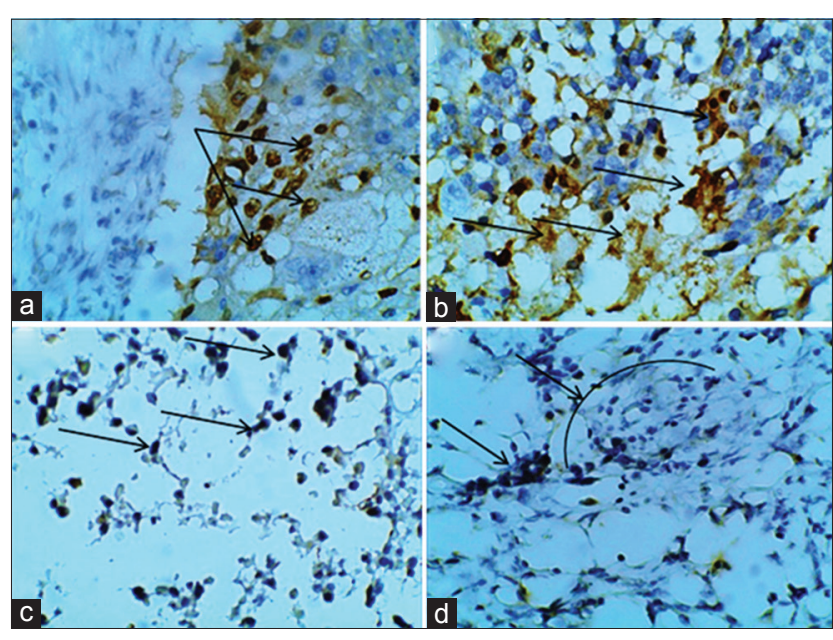

Fig. 2: The immunoexpression of 663 protein in metaplastic breast cancer patients with basal-like and non-basal-like types. (a) Nuclear P63, (b) cytoplasmic p63 with basal-like type, (c) nuclear P63, (d) cytoplasmic p63 with non-basal-like types. Those images were observed with a light microscope at a magnification of $400 \times$ (bar scale $30 \mu \mathrm{m}$ ). Arrows showed cytoplasmic and nuclear p63 markers

said that the distribution of cytoplasmic p63 immunoexpression may be affected by age, especially in breast carcinoma with basal-like type. Unlike the results of this research, the p63 was used as the myoepithelial marker to diagnose metaplastic carcinoma with a sensitivity of $65 \%$, a specificity of $96 \%$, a positive predictive value of $96 \%$, a negative predictive value of $66 \%$, and an accuracy of $78 \%$ [22]. 
The discrepancy of these findings can be assumed that age is a determinant factor of p63 immunoexpression in breast cancer with both basal-like and non-basal-like types. The weak frequency of p63 immunoexpression was found in the group of breast cancer with basal-like type aged 40-49 years. Meanwhile, the high frequency of p63 immunoexpression was found in the group of breast cancer with basal-like type aged 50-60 years old. The basal-like and TNBC were associated [23]. In addition, the expression of p 63 protein derived from basal epithelial cells is strongly influenced by the intensity of tumor cell development such as cell nutrition factor [24], chemotherapy, regulation, and p63 protein synthesis [25] both in nucleus and cytoplasm [26].

Furthermore, Fig. 1 illustrated that in the basal-like type, a cytoplasmic p63 protein was more dominant than nuclear p63 protein. However, in the non-basal-like type, a cytoplasmic p63 protein was lower than nuclear p63 protein. The p63 protein is a marker of squamous cell carcinoma at subcellular normal cells or hyperplastic ones appearing significantly in the epithelial cells and contributing to the increased invasion and aggressiveness of the tumor [26]. Specifically, the results of this research indicated that the sensitivity and specificity of cytoplasmic p63 protein in metaplastic breast cancer with basal-like type was $88.2 \%$, while the sensitivity and specificity of nuclear p 63 protein was $11.8 \%$. Unlike this research, the sensitivity and specificity of p63 as a diagnostic marker in metaplastic carcinoma reached $86.7 \%$ and $99.4 \%$ [27]. In addition, p63 can also be considered as a specific marker in metaplastic carcinoma [20]. In cases of TNBC breast cancer, breast tumor can specifically identify with basal-like type markers due to the intensity of expressions derived from the basal-like growth factor receptor 2 (HER2) of tumor cells [28].

Besides, Fig. 1 and Fig. 2 demonstrated that cytoplasmic p63 protein was more dominant than nuclear p63 protein. The cytoplasmic p63 protein is always associated with increased cancer mortality characterized by decreased apoptosis and increased proliferation activities of cancer cells [29]. Meanwhile, nuclear p63 protein is associated with oncogenic changes, and it has a lower sensitivity as a tumor marker than cytoplasmic p63 protein [30]. It means that cytoplasmic p63 protein has better sensitivity as a marker of metaplastic breast cancer. As a result, cytoplasmic p63 protein can be used as a prognosis for detecting metaplastic breast cancer with basal-like type.

\section{CONCLUSION}

Finally, it can be concluded that the frequency and distribution of cytoplasm p63 in all age groups of metaplastic breast cancer patients with the basal-like type was more dominant than the frequency and distribution of nuclear p63. However, in the nonbasal-like type, a cytoplasmic p63 protein was lower than nuclear p63 protein.

\section{ACKNOWLEDGMENTS}

We would like to acknowledge Dr. Hasan Sadikin Hospital in BandungIndonesia for providing research subjects. We also would like to gratitude to the Laboratory of Anatomy Pathology at Faculty of Medicine, University of Syiah Kuala, Banda Aceh-Indonesia and Faculty of Medicine, University of Sumatera Utara, Medan-Indonesia, also Faculty of Medicine, University of Padjajaran, Bandung-Indonesia, that it was facilitated the making of immunohistochemical samples and the reading of histoscores.

\section{REFERENCES}

1. Elgadir MA, Salama M, Adam A. Anti-breast cancer from various natural sources, review. Int J Pharm Pharm Sci 2015;7:44-7.

2. Gluz O, Liedtke C, Gottschalk N, Pusztai L, Nitz U, Harbeck N. Triplenegative breast cancer - Current status and future directions. Ann Oncol 2009;20:1913-27.
3. Jayakumar S, Haridass S, Krishnamurthy V. Anticancer activity of Punica Granatum rind extracts against human lung cancer cell line. Asian J Pharm Clin Res 2012;5 Suppl 2:204-10.

4. Boyle P. Triple-negative breast cancer: Epidemiological considerations and recommendations. Ann Oncol 2012;23 Suppl 6:vi7-12.

5. Zaha DC. Significance of immunohistochemistry in breast cancer. World J Clin Oncol 2014;5:382-92.

6. Su X, Chakravarti D, Flores ER. p63 steps into the limelight: Crucial roles in the suppression of tumorigenesis and metastasis. Nat Rev Cancer 2013; 13:136-43

7. Ferronika P, Triningsih FX, Ghozali A, Moeljono A, Rahmayanti S, Shadrina AN, et al. p63 cytoplasmic aberrance is associated with high prostate cancer stem cell expression. Asian Pac J Cancer Prev 2012;13:1943-8

8. Oncel S, Cosgul T, Calli A, Calli C, Pinar E. Evaluation of p53, p63, p21, p27, ki-67 in paranasal sinus squamous cell carcinoma and inverted papilloma. Indian J Otolaryngol Head Neck Surg 2011;63:172-7.

9. Kumala S, Septiseptiana EP, Meiyanto EE. Cytotoxic effect of secondary metabolites produced by endophytic fungi 1.3.11, 1.1.6 and 1.2.6 isolated from the fruit of "tanaman Buah Makassar" (Bruce janvanica (L.) merr) on in vitro T47D and MCF7 intact cells and identification of the fungus 1.3 .11 by ribosomal DNA sequence analysis. Int J Pharm Pharm Sci 2010;2:80-3.

10. Martin SE, Temm CJ, Goheen MP, Ulbright TM, Hattab EM. Cytoplasmic p63 immunohistochemistry is a useful marker for muscle differentiation: An immunohistochemical and immunoelectron microscopic study. Mod Pathol 2011;24:1320-6.

11. Barbareschi M, Pecciarini L, Cangi MG, Macrì E, Rizzo A, Viale G, et al. p63, a p53 homologue, is a selective nuclear marker of myoepithelial cells of the human breast. Am J Surg Pathol 2001;25:1054-60.

12. Arslan C, Dizdar O, Altundag K. Pharmacotherapy of triple-negative breast cancer. Expert Opin Pharmacother 2009;10:2081-93.

13. Hicks DG. Immunohistochemistry in the diagnostic evaluation of breast lesions. Appl Immunohistochem Mol Morphol 2011;19:501-5.

14. Won JR, Gao D, Chow C, Cheng J, Lau SY, Ellis MJ, et al. A survey of immunohistochemical biomarkers for basal-like breast cancer against a gene expression profile gold standard. Mod Pathol 2013;26:1438-50.

15. Zheng Z, Kye Y, Zhang X, Kim A, Kim I. Expression of p63, bcl-2, bcl-6 and p16 in basal cell carcinoma and squamous cell carcinoma of the skin. Korean J Pathol 2005;39:91-8.

16. Yadav R, Sen R, Chauhan P. ER, PR, HER2/NEU status and relation to clinicopathological factors in breast carcinoma. Int J Pharm Pharm Sci 2016;8:287-90.

17. Elsberger B, Lankston L, McMillan DC, Underwood MA, Edwards J. Presence of tumoural C-reactive protein correlates with progressive prostate cancer. Prostate Cancer Prostatic Dis 2011;14:122-8.

18. Tse GM, Tan PH, Chaiwun B, Putti TC, Lui PC, Tsang AK, et al. p63 is useful in the diagnosis of mammary metaplastic carcinomas. Pathology 2006;38:16-20.

19. Alluri P, Newman LA. Basal-like and triple-negative breast cancers: Searching for positives among many negatives. Surg Oncol Clin N Am 2014;23:567-77

20. Pellegrini G, Dellambra E, Golisano O, Martinelli E, Fantozzi I, Bondanza S, et al. p63 identifies keratinocyte stem cells. Proc Natl Acad Sci U S A 2001;98:3156-61.

21. Yoh KE, Regunath K, Guzman A, Lee SM, Pfister NT, Akanni O, et al. Repression of p63 and induction of EMT by mutant ras in mammary epithelial cells. Proc Natl Acad Sci U S A 2016;113:E6107-16.

22. Hsiao YH, Su YA, Tsai HD, Mason JT, Chou MC, Man YG. Increased invasiveness and aggressiveness in breast epithelia with cytoplasmic p63 expression. Int J Biol Sci 2010;6:428-42.

23. Koker MM, Kleer CG. p63 expression in breast cancer: A highly sensitive and specific marker of metaplastic carcinoma. Am J Surg Pathol 2004:28:1506-12.

24. Dellavalle RP, Walsh P, Marchbank A, Grayson TE, Su LJ, Parker ER, et al. CUSP/p63 expression in basal cell carcinoma. Exp Dermatol 2002;11:203-8

25. Mathelin C, Annane K, Treisser A, Chenard MP, Tomasetto C, Bellocq JP, et al. Pregnancy and post-partum breast cancer: A prospective study. Anticancer Res 2008;28:2447-52.

26. Hamsagayathri P, Sampath P. Performance analysis of breast cancer classification using decision tree classifiers. Int J Curr Pharm Res 2017;9:19-25

27. De Laurentiis M, Cianniello D, Caputo R, Stanzione B, Arpino G, Cinieri S, et al. Treatment of triple negative breast cancer (TNBC): Current options and future perspectives. Cancer Treat Rev 2010;36 Suppl 3:S80-6. 
28. Kesisis G, Kontovinis LF, Gennatas K, Kortsaris AH. Biological markers in breast cancer prognosis and treatment. J BUON 2010;15:447-54.

29. Dhillon PK, Barry M, Stampfer MJ, Perner S, Fiorentino M, Fornari A, et al. Aberrant cytoplasmic expression of $\mathrm{p} 63$ and prostate cancer mortality. Cancer Epidemiol Biomarkers Prev 2009;18:595-600

30. Narahashi T, Niki T, Wang T, Goto A, Matsubara D, Funata N, et al. Cytoplasmic localization of p63 is associated with poor patient survival in lung adenocarcinoma. Histopathology 2006;49:349-57. 